\title{
Lead reduces tension development and the myosin ATPase activity of the rat right ventricular myocardium
}

\author{
D.V. Vassallo ${ }^{1,2}$, E.C. Lebarch ${ }^{1}$, C.M. Moreira ${ }^{1}$, G.A. Wiggers ${ }^{1}$ and I. Stefanon ${ }^{1,2}$ \\ ${ }^{1}$ Departamento de Ciências Fisiológicas, Universidade Federal do Espírito Santo, Vitória, ES, Brasil \\ ${ }^{2}$ Centro de Ciências da Saúde de Vitória, Escola de Medicina da Santa Casa de Misericórdia, Vitória, \\ ES, Brasil
}

Correspondence to: D.V. Vassallo, Departamento de Ciências Fisiológicas, CBM, UFES, Av. Marechal Campos, 1468, 29040-095 Vitória, ES, Brasil

Fax: +55-27-335-7330. E-mail: daltonv2@terra.com.br

\begin{abstract}
Lead $\left(\mathrm{Pb}^{2+}\right)$ poisoning causes hypertension, but little is known regarding its acute effects on cardiac contractility. To evaluate these effects, force was measured in right ventricular strips that were contracting isometrically in 45 male Wistar rats (250-300 g) before and after the addition of increasing concentrations of lead acetate $(3,7,10,30,70,100$, and $300 \mu \mathrm{M})$ to the bath. Changes in rate of stimulation $(0.1-1.5 \mathrm{~Hz})$, relative potentiation after pauses of 15,30 , and $60 \mathrm{~s}$, effect of $\mathrm{Ca}^{2+}$ concentration $(0.62,1.25$, and $2.5 \mathrm{mM})$, and the effect of isoproterenol $(20 \mathrm{ng} / \mathrm{mL})$ were determined before and after the addition of $100 \mu \mathrm{M} \mathrm{Pb}{ }^{2+}$. Effects on contractile proteins were evaluated after caffeine treatment using tetanic stimulation (10 $\mathrm{Hz}$ ) and measuring the activity of the myosin ATPase. $\mathrm{Pb}^{2+}$ produced concentration-dependent force reduction, significant at concentrations greater than $30 \mu \mathrm{M}$. The force developed in response to increasing rates of stimulation became smaller at 0.5 and $0.8 \mathrm{~Hz}$. Relative potentiation increased after $100 \mu \mathrm{M} \mathrm{Pb}^{2+}$ treatment. Extracellular $\mathrm{Ca}^{2+}$ increment and isoproterenol administration increased force development but after $100 \mu \mathrm{M} \mathrm{Pb}^{2+}$ treatment the force was significantly reduced suggesting an effect of the metal on the sarcolemmal $\mathrm{Ca}^{2+}$ influx. Concentration of $100 \mu \mathrm{M} \mathrm{Pb}^{2+}$ also reduced the peak and plateau force of tetanic contractions and reduced the activity of the myosin ATPase. Results showed that acute $\mathrm{Pb}^{2+}$ administration, although not affecting the sarcoplasmic reticulum activity, produces a concentration-dependent negative inotropic effect and reduces myosin ATPase activity. Results suggest that acute lead administration reduced myocardial contractility by reducing sarcolemmal calcium influx and the myosin ATPase activity. These results also suggest that lead exposure is hazardous and has toxicological consequences affecting cardiac muscle.
\end{abstract}

Key words: Lead; Right ventricular strips; Contraction; Heart; Myosin ATPase activity

Research supported by FAPES/FUNCITEC (\#003/2008) and CNPq (\#471610/2006-2).

Received October 25, 2007. Accepted August 25, 2008

\section{Introduction}

Lead is an environmental contaminant that damages the human organism harming neural, renal and cardiovascular systems, among others (1-4). Harmful effects depend on plasma levels and on the duration of exposure. Individuals with blood lead levels up to $29 \mu \mathrm{g} / \mathrm{dL}$ (1 to 1.4 $\mu \mathrm{mol} / \mathrm{L})$, currently considered to be an unsafe level, had $46 \%$ increased all-cause mortality, 39\% increased circulatory mortality and $68 \%$ increased cancer mortality (5).
Previous research reported that exposure to low levels of lead causes hypertension in animals and humans $(6,7)$. Analyzing data from the Third National Health and Nutrition Examination Survey (NHANES, 1988-1994), a positive correlation was reported between plasma lead concentration and arterial pressure in black men and women (8).

The etiology of lead-induced hypertension is reported to be caused by the inhibition of $\mathrm{Na}, \mathrm{K}-\mathrm{ATP}$ ase (9) and from the reduced bioavailability of nitric oxide plus an increased 
endothelial release of endothelin $(10,11)$. The participation of free radicals reducing nitric oxide bioavailability (12) and depletion of antioxidant reserves (4) or its upregulation (13) has been reported. Lead-induced hypertension also involves the participation of peripheral or central nervous system mechanisms, such as the increase of sympathetic nerve activity, reduction of the baroreflex sensitivity and reduction of parasympathetic tone $(14,15)$.

Although lead-induced hypertension is well described, few reports evaluated the effect of lead on the cardiac muscle. Carmignani et al. $(11,15)$ reported increased myocardial inotropism and increased activity of the angiotensin-converting enzyme in rats exposed to $60 \mathrm{ppm}$ lead acetate for 10 months. On the other hand, Williams et al. (16) reported negative inotropic effects on perfused hearts caused by acute lead administration. Prentice and Kopp (17) reported that lead significantly attenuated positive inotropic response to increasing calcium concentrations in perfused hearts. Bernal et al. (18) reported a calcium channel blocker action of lead in rat myocytes and Xenopus laevis oocytes.

Thus, the objective of this study was to determine the acute action of increasing concentrations of lead acetate on the contractile activity of the isolated rat ventricular myocardium by measuring isometric twitch and tetanic contractions of right ventricular strips, as well as the effect on the myosin ATPase activity of rat hearts.

\section{Material and Methods}

Studies were performed on male Wistar rats (250-300 g). All experiments were conducted in compliance with the guidelines for biomedical research as stated by the Brazilian Societies of Experimental Biology. All rats had free access to water and were fed rat chow ad libitum.

\section{Right ventricular strips}

Rats were anesthetized with sodium pentobarbital (65 $\mathrm{mg} / \mathrm{kg}, \mathrm{ip}$ ), the thorax was opened and the hearts were removed rapidly. The hearts were perfused through the aortic stump with modified Tyrode solution $(120 \mathrm{mM} \mathrm{NaCl}$, $5.4 \mathrm{mM} \mathrm{KCl}, 1.2 \mathrm{mM} \mathrm{MgCl}_{2}, 1.25 \mathrm{mM} \mathrm{CaCl}_{2}, 2 \mathrm{mM} \mathrm{HEPES}$ buffer, and $11 \mathrm{mM}$ glucose, $\mathrm{pH}$ was adjusted to 7.4 with 4 $\mathrm{M} \mathrm{NaOH}$ ) to permit the proper selection and dissection of the right ventricle strips. The preparations were immersed in a $50-\mathrm{mL}$ water-jack bath maintained at $26 \pm 0.5^{\circ} \mathrm{C}$ and gassed with $100 \% \mathrm{O}_{2}$ to avoid hypoxia of the muscle core. Preparations were attached to an isometric transducer (Nihon-Kohden RMP-600, Japan). Field stimulation was provided by isolated rectangular pulses $(10-15 \mathrm{~V}, 5-10 \mathrm{~ms}$ duration) applied through a pair of platinum electrodes placed along the entire muscle extension. The standard rate of stimulation was $0.5 \mathrm{~Hz}$. Recordings started after $45-$ $60 \mathrm{~min}$ to let the beating preparation adapt to the new environmental conditions. The force developed during contractions was measured as $\mathrm{mN}$ of developed force divided by $\mathrm{g}$ of muscle weight $(\mathrm{mN} / \mathrm{g})$. The correction by the strip weight was used to normalize the data from different preparations.

In the first protocol (strip weight $=24.8 \pm 1.64 \mathrm{mg}, \mathrm{N}=$ $8)$, concentration-response curves to increasing concentrations of lead acetate $(3,7,10,30,70,100$, and $300 \mu \mathrm{M})$ were performed. Tests were performed at Lmax (optimum length for contraction) and peak isometric force, time to peak tension and relaxation time were measured.

The action of $100 \mu \mathrm{M}$ lead acetate was evaluated by the following protocols: post-rest potentiation; change of rate of stimulation $(0.1,0.3,0.5,0.8,1$, and $1.5 \mathrm{~Hz}$; strip weight $=17.3 \pm 1.64 \mathrm{mg} ; \mathrm{N}=8$ ); change of external $\mathrm{Ca}^{2+}$ concentration $(0.62,1.25$, and $2.5 \mathrm{mM}$; strip weight $=16 \pm$ $1.36 \mathrm{mg} ; \mathrm{N}=8)$, and administration of isoproterenol (20 ng/ $\mathrm{mL}$; strip weight $=14.8 \pm 1.35 \mathrm{mg} ; \mathrm{N}=11$ ). The post-rest potentiation was obtained after pause intervals of 15,30 , and $60 \mathrm{~s}$ and the results are presented as relative potentiation (the amplitude of post-rest contractions divided by steady-state contractions) to compare potentiations after steady-state contractions of different amplitudes. Since the rat myocardium saturates its positive inotropic response at extracellular $\mathrm{Ca}^{2+}$ concentrations smaller than that for other species (19), protocols using $20 \mathrm{ng} / \mathrm{mL}$ isoproterenol were performed in the presence of low extracellular $\mathrm{Ca}^{2+}$ concentrations $(0.62 \mathrm{mM})$. For this group of experiments, the concentration of $100 \mu \mathrm{M}$ lead acetate was used because it reduced isometric tension to approximately $30 \%$ of control tension (Figure 1).

In the last protocol (strip weight $=14.5 \pm 1.06 \mathrm{mg} ; \mathrm{N}=$ $10)$, tetanic tension was elicited, before and after $100 \mu \mathrm{M}$ lead acetate treatments by high frequency stimulation ( 5 $\mathrm{Hz}$ for 5-10 s). Tetanus was achieved after $5 \mathrm{mM}$ caffeine (B. Herzog, Brazil) pretreatment for $30 \mathrm{~min}$ and a time interval of 15 min was used between tetanic stimulations.

\section{Myosin ATPase activity}

To determine if lead acetate is capable of affecting myosin ATPase activity, the effects of this metal were assayed as described previously $(20,21)$. Briefly, myosin was prepared from minced and homogenized right ventricles $(\mathrm{N}=7)$, extracted briefly with $\mathrm{KCl}$ phosphate buffer (0.3 M KCl, 0.2 M phosphate buffer, $\mathrm{pH}$ 6.5) (22).

Myosin ATPase activity was assayed by measuring $\mathrm{Pi}$ liberation from $1 \mathrm{mM}$ ATP in the presence of $50 \mathrm{mM}$ HEPES, pH 7, 0.6 M KCl, $5 \mathrm{mM} \mathrm{CaCl}_{2}$, or $10 \mathrm{mM} \mathrm{EGTA} \mathrm{(N}$ 
= 7) in the absence and in the presence of $100 \mu \mathrm{M}$ lead acetate.

Under this high ionic strength and no $\mathrm{Mg}^{2+}$ in the medium, only myosin activity was measured and there is no significant $\mathrm{Ca}^{2+}$-ATPase activity from sarcoplasmic reticulum membranes, which requires high $\mathrm{Mg}^{2+}$ and low $\mathrm{Ca}^{2+}$ concentrations. Controls with addition of the enzyme preparation after addition of trichloroacetic acid were used to correct for nonenzymatic hydrolysis of the substrate. All measurements were performed in duplicate. The enzyme activity was calculated as the difference between the activities observed in the presence of $\mathrm{Ca}^{2+}$ and in the presence of $10 \mathrm{mM}$ EGTA. Inorganic phosphate was determined by the method of Chan et al. (23). The specific activity was reported as nmol Pi released per min per $\mathrm{mg}$ of protein unless otherwise stated. Protein was measured by the Coomassie blue method according to Bradford (24) using bovine serum albumin as standard.

\section{Drugs}

The following drugs were used: sodium pentobarbital (Cristalia Produtos Químicos Farmacêuticos Ltda., Brazil), heparin (Roche Q.F.S.A., Brazil), anhydrous caffeine (B. Herzog), bovine serum albumin, lead acetate, HEPES and (-) isoproterenol hydrochloride (Sigma Chemical Co., USA). All other reagents used were of analytical grade from Sigma, E. Merck (Germany) or Reagen (Brazil).

\section{Statistical analysis}

The results are reported as means \pm SEM with $N$ indicating the number of observations. Values were analyzed using the Student $t$-test and ANOVA (one- or twoway). When ANOVA showed a significant difference, the Tukey test was applied. $\mathrm{P}<0.05$ was considered to be significant. Analysis of the data and plotting of the figures were carried out using GraphPad Prism ${ }^{\mathrm{TM}}$ (version 2.0, GraphPad Software, USA) and GB-STAT (version 4.0, Dynamic Microsystem Inc., USA).

\section{Results}

Figure 1 shows the effects of increasing concentrations of lead acetate on isometric force developed by right ventricular strips. There was a concentration-dependent force reduction that reached a $25 \%$ reduction with $100 \mu \mathrm{M}$ lead acetate compared to the control. However, there were no concentration-dependent alterations of the time parameters time to peak tension and relaxation time of the isometric contractions (data not shown).

Post-rest potentiation was used to determine if lead could affect the function of the sarcoplasmic reticulum.
Post-rest potentiated contractions obtained after pauses of 15,30 , and $60 \mathrm{~s}$ were recorded and analyzed as relative potentiation before and after $100 \mu \mathrm{M}$ lead acetate administration (Figure 2). Lead reduced the magnitude of steadystate contractions but induced a progressive increase in relative potentiation (force under steady-state conditions: control $=829 \pm 65.5 \mathrm{mN} / \mathrm{g}$; lead $=560 \pm 43.3 \mathrm{mN} / \mathrm{g} ; \mathrm{P}<$ 0.05).

To determine if lead interferes with the muscle response to positive inotropic intervention, changes of external $\mathrm{Ca}^{2+}$ concentration and isoproterenol administration

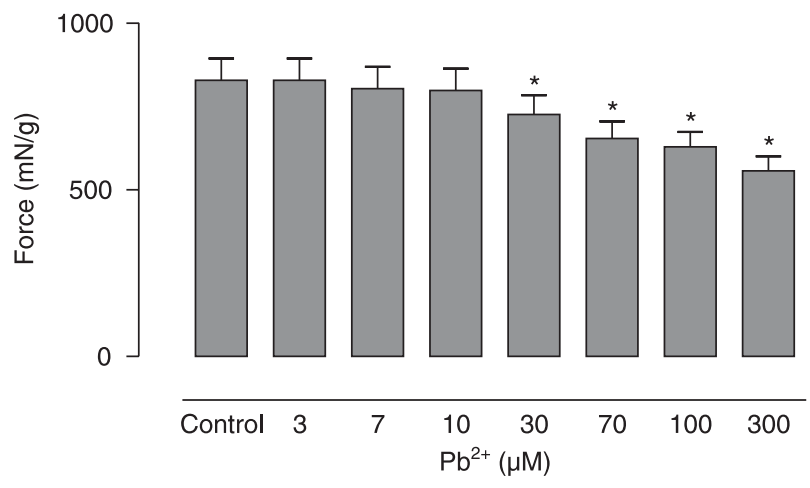

Figure 1. Effects of increasing $\mathrm{Pb}^{2+}$ concentration on the isometric force of rat right ventricular strips. Data are reported as means \pm SEM for $\mathrm{N}=8$ measuremnts. ${ }^{*} \mathrm{P}<0.01, \mathrm{~Pb}^{2+} v s$ control (one-way ANOVA, repeated measures).

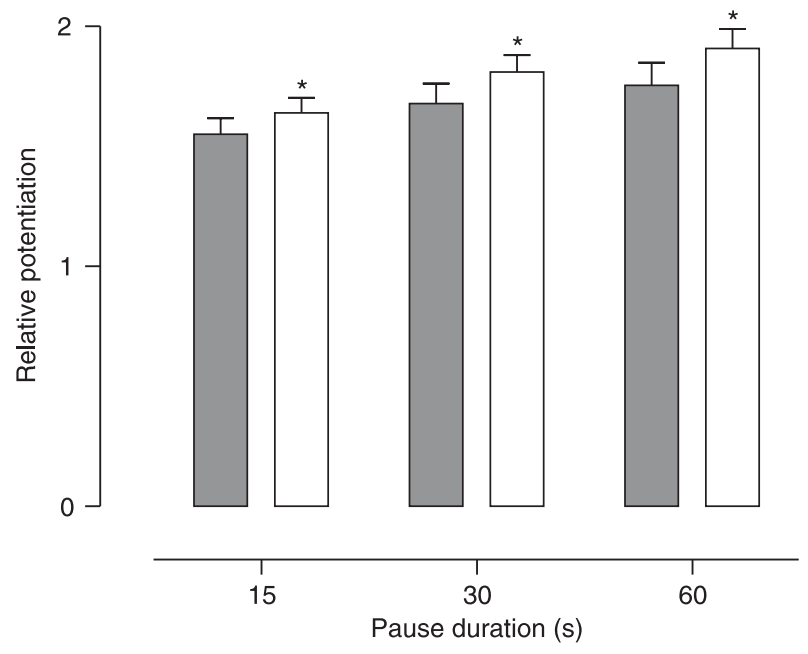

Figure 2. Effect of $100 \mu \mathrm{M} \mathrm{Pb}^{2+}$ on the relative potentiation (ratio of post-rest contractions and steady-state contractions) of isometric contractions of right ventricular strips obtained after pauses of 15,30 , and $60 \mathrm{~s}$. Control: filled columns; after $\mathrm{Pb}^{2+}$ : open columns. Rate of stimulation at $0.5 \mathrm{~Hz}$. Data are reported as means \pm SEM for $\mathrm{N}=8$ measurements. ${ }^{*} \mathrm{P}<0.05, \mathrm{~Pb}^{2+} v s$ control (two-way ANOVA, repeated measures). 

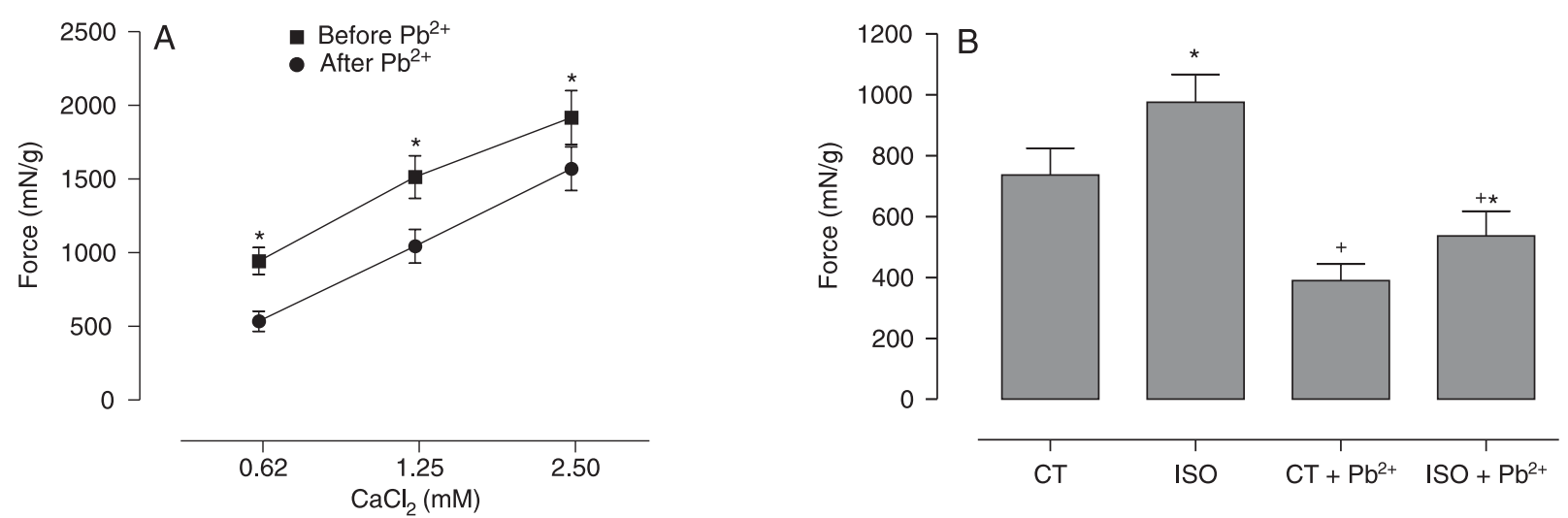

Figure 3. Effects of $100 \mu \mathrm{M} \mathrm{Pb}^{2+}$ on positive inotropic interventions produced by different $(0.62,1.25$, and $2.5 \mathrm{mM})$ calcium concentrations (A) and $20 \mathrm{ng} / \mathrm{mL}$ isoproterenol (ISO; B) on the isometric contractions of right ventricular strips. Rate of stimulation: 0.5 $\mathrm{Hz}$. Data are reported as means $\pm \mathrm{SEM}$ for $\mathrm{N}=8$ (calcium changes) or $\mathrm{N}=11$ (ISO measurements). $A$, ${ }^{*} \mathrm{P}<0.05, \mathrm{~Pb}^{2+} v s$ control (twoway ANOVA, repeated measures). $B$, ${ }^{*} \mathrm{P}<0.05$, ISO vs $\mathrm{CT}$ before and after $\mathrm{Pb}^{2+}$, and ${ }^{+} \mathrm{P}<0.05, \mathrm{CT}+\mathrm{Pb}^{2+}$ vs $\mathrm{CT}$ and ISO $+\mathrm{Pb}^{2+} v s$ ISO (one-way ANOVA, repeated measures).

were investigated. The dependence of force development upon changes in external $\mathrm{Ca}^{2+}(0.62,1.25$, and $2.5 \mathrm{mM})$ in the absence and presence of lead acetate (Figure $3 \mathrm{~A}$ ) showed that, under control conditions and after lead administration, $\mathrm{Ca}^{2+}$ increased the force in a concentrationdependent way. However, in the presence of $100 \mu \mathrm{M}$ lead acetate, the increased force induced by $\mathrm{Ca}^{2+}$ was signifi-

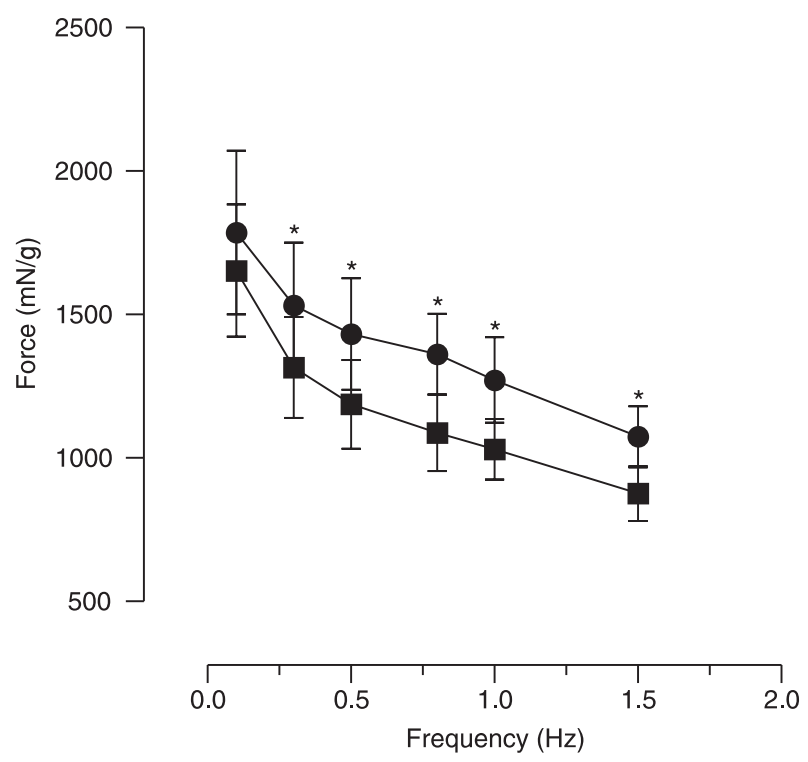

Figure 4. Effects of $100 \mu \mathrm{M} \mathrm{Pb}^{2+}$ on the isometric contractions of right ventricular strips at increasing rates of stimulation. Squares $=\mathrm{Pb}^{2+}$; circles $=$ control. Data are reported as means \pm SEM for $\mathrm{N}=8$ measurements. ${ }^{*} \mathrm{P}<0.05, \mathrm{~Pb}^{2+}$ vs control (two-way ANOVA, repeated measures). cantly $(\mathrm{P}<0.05)$ less compared with the control condition. Using isoproterenol $(20 \mathrm{ng} / \mathrm{mL})$, the expected positive inotropic effect was elicited (Figure 3B) and the force increment produced by isoproterenol also occurred in the presence of $100 \mu \mathrm{M}$ lead acetate but with a reduced magnitude.

Figure 4 shows the effects of $100 \mu \mathrm{M}$ lead acetate on changes in force by increasing the rate of stimulation. Lead reduced isometric force development even when the rate changed $(0.1,0.3,0.5,0.8,1.0$, and $1.5 \mathrm{~Hz})$. In the control group, force reduction was observed as the rate increased. The same pattern was observed in the lead-treated group but with a reduced magnitude.

We also determined if the depressant effect of lead acetate was mediated solely via $\mathrm{Ca}^{2+}$ influx or whether it could directly affect contractile proteins. To examine this possibility, we tested the effects of $100 \mu \mathrm{M}$ lead acetate on tetanic contractions. Tetanic contractions developed a fast upstroke (tetanic peak force) followed by a slow decay (tetanic plateau force). Lead acetate depressed force development of both the tetanic peak (control $=1348 \pm 167 \mathrm{vs}$ lead $=859 \pm 132 \mathrm{mN} / \mathrm{g} ; \mathrm{P}<0.05)$ and the tetanic plateau force (control $=902 \pm 141 \mathrm{vs}$ lead $=608 \pm 76.7 \mathrm{mN} / \mathrm{g} ; \mathrm{P}<$ $0.05)$ developed by the ventricular strips. To show a direct effect on the contractile proteins and because development of tension also depends on myosin ATPase activity (21), we investigated if lead acetate could reduce the activity of this enzyme. Myosin $\mathrm{Ca}^{2+}$-ATPase activity was assayed in the presence of $100 \mu \mathrm{M}$ lead acetate showing a reduction in percent $($ control $=100 \%$ and lead $=74.3 \pm$ $8.61 \% ; \mathrm{P}<0.05, t$-test, repeated measures). 


\section{Discussion}

The results presented here suggest that increasing concentrations of lead acetate reduced the development of isometric force and tetanic tension, and the activity of the myosin ATPase without affecting sarcoplasmic reticulum activity.

The toxic effects of lead in neural tissue and vessels are well described. In the neural tissue, lead acts by inhibiting $\mathrm{Na}, \mathrm{K}-\mathrm{ATPase}$, increasing the production of free radicals, which results in neural lesions $(4,25)$. A hypertensive effect was also reported and the action of lead is related to impairment of endothelial function and also to the production of free radicals $(4,13,26)$. An increased production of angiotensin II has also been reported as a mechanism to induce hypertension (15).

Albeit the mechanisms of lead-induced hypertension and its vascular effects are already known, cardiac actions are poorly described. Few reports show that chronic lead administration acts on the heart enhancing contractility probably by increasing the production of angiotensin II (15). Although chronic treatment increases contractility, acute treatment blocks calcium channels in cardiac myocytes and Xenopus laevis oocytes (18). These findings suggest that lead affects the heart. We, thus, investigated the actions of acute administration of increasing concentrations of lead on the isolated cardiac muscle.

Our results showed a concentration-dependent negative inotropic effect induced by the metal that became significant at $30 \mu \mathrm{M}$. This force reduction was not followed by significant changes in temporal parameters. The blockade of calcium channels could explain the force reduction. However, the fact that lead binds to sulfhydryl ( $\mathrm{SH}$ ) groups suggests that the metal could affect contractile proteins $(27,28)$. The activity of myosin, for example, is reduced by $\mathrm{Hg}$, which also binds to $\mathrm{SH}$ groups (21).

To investigate the effects of lead on contractile proteins, tetanic contractions and the activity of myosin ATPase were used. Tetanic stimulation obtained after inhibition of sarcoplasmic reticulum activity with caffeine or ryanodine has been used to produce maximal activation of the contractile machinery in the intact myocardium $(29,30)$. Caffeine acts by emptying the sarcoplasmic reticulum of its calcium content and the sustained exposure to caffeine prevents sarcoplasmic reticulum $\mathrm{Ca}^{2+}$ accumulation (31). Since relaxation in the rat myocardium is a process mainly dependent on sarcoplasmic reticulum $\mathrm{Ca}^{2+}$ reuptake, and because rat myocardium has action potentials of short duration and short refractory period, these features facilitate the development of tetanic contractions $(32,33)$. Peak force and plateau force developed by ventricular strips treated with lead and under tetanic stimulations were depressed. Once the sarcoplasmic reticulum activity is blocked, tetanic contractions depend only on calcium influx or on the activity of myosin ATPase. Thus, our results suggest that lead reduced the sarcolemmal $\mathrm{Ca}^{2+}$ influx or affected contractile proteins.

To investigate if tetanic tension reduction was also dependent on the effects on the contractile proteins, the effect of lead on myosin ATPase activity was investigated. With $100 \mu \mathrm{M}$ lead, the activity of myosin ATPase was reduced. This effect is reasonable because lead binds to $\mathrm{SH}$ groups (28) and the myosin molecule contains several $\mathrm{SH}$ groups (27), and furthermore lead depletes glutathione and protein-bound $\mathrm{SH}$ groups (25).

Time to peak tension and relaxation time depend on how fast the activator calcium reaches the contractile apparatus and the capacity of the myocyte to reduce myoplasmic calcium. Mercury, for example, reduces time to peak tension by increasing calcium release from the sarcoplasmic reticulum upon activation $(34,35)$. In the rat myocardium, both kinetic parameters depend mainly on the release of calcium upon activation of the sarcoplasmic reticulum and the reuptake of calcium during relaxation (36). The lack of effects on kinetic parameters supports the finding obtained with the post-rest potentiation, which was not affected by lead. When analyzing the relative potentiation, it was observed that albeit reduction of force of the steady-state contractions occurred, the relative potentiation increased. This result suggests that the effect of lead depends more on membrane $\mathrm{Ca}^{2+}$ influx through voltagesensitive channels than on $\mathrm{Ca}^{2+}$ released from the sarcoplasmic reticulum. Similar behavior was reported using verapamil and manganese, both $\mathrm{Ca}^{2+}$ channel blockers (37), which reduce the transmembrane $\mathrm{Ca}^{2+}$ influx during activation but do not affect sarcoplasmic reticulum activity. Therefore, if $\mathrm{Ca}^{2+}$ entry is partially blocked, the relative participation of the sarcoplasmic reticulum in tension development increases and the first contraction after pause is potentiated (37).

To determine if lead could change the capacity of response to inotropic interventions, the increase of external calcium concentrations, isoproterenol administration and changes in the rate of stimulation were performed in the absence and presence of the metal. When inotropic interventions were induced in the presence of lead, force was reduced but no changes in the pattern of the inotropic interventions were observed. This force reduction was maintained even when the muscle was under inotropic interventions, such as increased extracellular $\mathrm{Ca}^{2+}$ concentration or changes in the rate of stimulation. This is an interesting finding that suggests that the negative inotropic 
action of lead takes place without blunting the pattern of the positive inotropic actions. The maintenance of the pattern of those inotropic effects at lower force values and the increase of relative potentiation described above reinforce the suggestion that lead might act as a calcium channel blocker, as previously reported (18).

The present findings reinforce the biological significance of lead as an environmental contaminant that damages the human organism producing harmful effects to the cardiovascular system. Although significant progress has occurred regarding environmental contamination, there are still serious problems produced by heavy metals. The positive correlation between plasma lead concentration and hypertension (6-8), one of the most prominent cardiovascular problems in many countries, and the increase of

\section{References}

1. Nriagu JO. Saturnine gout among Roman aristocrats. Did lead poisoning contribute to the fall of the Empire? N Engl $J$ Med 1983; 308: 660-663.

2. Gilfillan SC. Lead poisoning and the fall of Rome. J Occup Med 1965; 7: 53-60.

3. World Health Organization. Environmental health criteria 165: inorganic lead. In: WHO (Editor), International Programme on Chemical Safety (IPCS). Geneve: 1995.

4. Patrick L. Lead toxicity part II: the role of free radical damage and the use of antioxidants in the pathology and treatment of lead toxicity. Altern Med Rev 2006; 11: 114-127.

5. Lustberg M, Silbergeld E. Blood lead levels and mortality. Arch Intern Med 2002; 162: 2443-2449.

6. Harlan WR. The relationship of blood lead levels to blood pressure in the U.S. population. Environ Health Perspect 1988; 78: 9-13.

7. Navas-Acien A, Guallar E, Silbergeld EK, Rothenberg SJ. Lead exposure and cardiovascular disease - a systematic review. Environ Health Perspect 2007; 115: 472-482.

8. Vupputuri S, He J, Muntner P, Bazzano LA, Whelton PK, Batuman V. Blood lead level is associated with elevated blood pressure in blacks. Hypertension 2003; 41: 463-468.

9. Weiler E, Khalil-Manesh F, Gonick HC. Effects of lead and a low-molecular-weight endogenous plasma inhibitor on the kinetics of sodium-potassium-activated adenosine triphosphatase and potassium-activated p-nitrophenylphosphatase. Clin Sci 1990; 79: 185-192.

10. Khalil-Manesh F, Gonick HC, Weiler EW, Prins B, Weber MA, Purdy RE. Lead-induced hypertension: possible role of endothelial factors. Am J Hypertens 1993; 6: 723-729.

11. Carmignani M, Volpe AR, Boscolo $P$, Qiao N, Di Gioacchino $\mathrm{M}$, Grilli $\mathrm{A}$, et al. Catecholamine and nitric oxide systems as targets of chronic lead exposure in inducing selective functional impairment. Life Sci 2000; 68: 401-415.

12. Vaziri ND, Ding $Y, N i Z$. Compensatory up-regulation of nitric-oxide synthase isoforms in lead-induced hypertension; reversal by a superoxide dismutase-mimetic drug. $J$ all-cause mortality, including circulatory and cancer mortality (5), reinforce the biological significance of lead as an important hazard.

The main new findings presented here suggest that acute lead administration although not affecting sarcoplasmic reticulum activity, reduced myocardial contractility by reducing sarcolemmal calcium influx and the myosin ATPase activity. These findings also indicate that lead, in addition of being an important hazard, is a risk factor capable to affect cardiac function.

\section{Acknowledgments}

We are very grateful to Professor Carlos Tito de Sá Cunha for the careful English revision of the manuscript.

Pharmacol Exp Ther 2001; 298: 679-685.

13. Farmand F, Ehdaie A, Roberts CK, Sindhu RK. Lead-induced dysregulation of superoxide dismutases, catalase, glutathione peroxidase, and guanylate cyclase. Environ Res 2005; 98: 33-39.

14. Boscolo P, Carmignani M, Carelli G, Finelli VN, Giuliano G. Zinc and copper in tissues of rats with blood hypertension induced by long-term lead exposure. Toxicol Lett 1992; 63: 135-139.

15. Carmignani M, Boscolo P, Poma A, Volpe AR. Kininergic system and arterial hypertension following chronic exposure to inorganic lead. Immunopharmacology 1999; 44: 105110.

16. Williams BJ, Hejtmancik MR Jr, Abreu M. Cardiac effects of lead. Fed Proc 1983; 42: 2989-2993.

17. Prentice RC, Kopp SJ. Cardiotoxicity of lead at various perfusate calcium concentrations: functional and metabolic responses of the perfused rat heart. Toxicol Appl Pharmacol 1985; 81: 491-501.

18. Bernal J, Lee JH, Cribbs LL, Perez-Reyes E. Full reversal of $\mathrm{Pb}^{2+}$ block of L-type $\mathrm{Ca}^{2+}$ channels requires treatment with heavy metal antidotes. J Pharmacol Exp Ther 1997; 282: 172-180.

19. Vassallo DV, Lima EQ, Campagnaro P, Stefanon I, Leite $\mathrm{CM}$, Mill JG. Effects of isoproterenol on the mechanical activity of isolated papillary muscles and perfused rat hearts in various calcium concentrations. Pharmacol Res 1994; 29: 251-260.

20. Delcayre C, Swynghedauw B. A comparative study of heart myosin ATPase and light subunits from different species. Pflugers Arch 1975; 355: 39-47.

21. Cappelli V, Bottinelli R, Poggesi C, Moggio R, Reggiani C. Shortening velocity and myosin and myofibrillar ATPase activity related to myosin isoenzyme composition during postnatal development in rat myocardium. Circ Res 1989; 65: 446-457.

22. Bremel RD, Weber A. Calcium binding to rabbit skeletal 
myosin under physiological conditions. Biochim Biophys Acta 1975; 376: 366-374.

23. Chan KM, Delfert $D$, Junger KD. A direct colorimetric assay for $\mathrm{Ca}^{2+}$-stimulated ATPase activity. Anal Biochem 1986; 157: 375-380.

24. Bradford MM. A rapid and sensitive method for the quantitation of microgram quantities of protein utilizing the principle of protein-dye binding. Anal Biochem 1976; 72: 248-254.

25. Stohs SJ, Bagchi D. Oxidative mechanisms in the toxicity of metal ions. Free Radic Biol Med 1995; 18: 321-336.

26. Vaziri ND. Pathogenesis of lead-induced hypertension: role of oxidative stress. J Hypertens Suppl 2002; 20: S15-S20.

27. Flink IL, Rader JH, Banerjee SK, Morkin E. Atrial and ventricular cardiac myosins contain different heavy chain species. FEBS Lett 1978; 94: 125-130.

28. Anner BM, Moosmayer M, Imesch E. Mercury blocks Na-KATPase by a ligand-dependent and reversible mechanism. Am J Physiol 1992; 262: F830-F836.

29. Moreira CM, Oliveira EM, Bonan CD, Sarkis JJ, Vassallo DV. Effects of mercury on myosin ATPase in the ventricular myocardium of the rat. Comp Biochem Physiol C Toxicol Pharmacol 2003; 135C: 269-275.

30. Yue DT, Marban E, Wier WG. Relationship between force and intracellular $\left[\mathrm{Ca}^{2+}\right]$ in tetanized mammalian heart muscle. J Gen Physiol 1986; 87: 223-242.

31. Leite CM, Vassallo DV, Mill JG. Characteristics of tetanic contractions in caffeine-treated rat myocardium. Can $\mathrm{J}$ Physiol Pharmacol 1995; 73: 638-643.

32. Bassani JW, Bassani RA, Bers DM. Relaxation in rabbit and rat cardiac cells: species-dependent differences in cellular mechanisms. J Physiol 1994; 476: 279-293.

33. Aronson RS. Characteristics of action potentials of hypertrophied myocardium from rats with renal hypertension. Circ Res 1980; 47: 443-454.

34. Marban E, Wier WG. Ryanodine as a tool to determine the contributions of calcium entry and calcium release to the calcium transient and contraction of cardiac Purkinje fibers. Circ Res 1985; 56: 133-138.

35. Brunder DG, Dettbarn C, Palade P. Heavy metal-induced $\mathrm{Ca}^{2+}$ release from sarcoplasmic reticulum. J Biol Chem 1988; 263: 18785-18792.

36. Oliveira EM, Vassallo DV, Sarkis JJ, Mill JG. Mercury effects on the contractile activity of isolated heart muscle. Toxicol Appl Pharmacol 1994; 128: 86-91.

37. Bers DM. Cardiac excitation-contraction coupling. Nature 2002; 415: 198-205. 